\title{
STRATEGIES SNARKS AND STORIES: SME OWNER MANAGER PERCEPTIONS OF BUSINESS ADVISERS
}

\begin{abstract}
Purpose The aim is to examine the perceptions of small business entrepreneurs regarding the efficacy of external business advisers in delivering sustainable strategic and operational guidance.
\end{abstract}

Design/methodology/approach The research is interpretivist, exploring the narratives of SME owner/managers in manufacturing. Five in depth interviews were carried out, revealing a range of decision stories about the use of external business advisers.

Research limitations/implications A small scale study, it would be worthwhile to examine the perceptions of additional entrepreneurs to business advisers, in order to compare research findings.

Findings Whilst there was some scepticism towards the use of advisers in certain situations, the research revealed that levels of trust, relationship building and the credibility of the consultant are substantial factors in determining whether the engagement is successful or not.

Practical implications Policy regarding advice to small businesses should be framed in terms of the local context of the firm and its owner, rather than on broad and generalisable systems of business knowledge. Time and effort is required in order to build a sustainable relationship between advisers and owners and it is recommended particular attention is paid to the process.

Social implications The research suggests that potentially, industrial policy regarding current delivery of small business advice requires readjustments towards more of a relationship focus.

Originality/value Little established research appears to exist in relation to the tendency or otherwise, for SME decision makers to pursue and utilise external advice. This paper helps to fill an important gap in the literature whilst offering some significant and nuanced insights into the perceptions of SME owner managers.

Keywords: SME manufacturing, Business advice, Interpretative, Strategy and Operations Narrative 


\section{Introduction: Searching for the Snark}

Hughes (2009) likens attempts at interpreting small firm strategy to Lewis Carroll's poem, The Hunting of the Snark (Carroll 2012). The mythological status of the latter gives those who find the beast, the promise of all sorts of benefits when captured. This is analogous to the idea that a considerable amount of business policy is aimed at supporting small firms, which it is claimed, can offer all sorts of benefits to company owners, the economy and society. As Hughes (2009) points out, over the years, a plethora of schemes have been put in place, intending to 'capture' an effective strategy that will best serve the above interests. These wide and general systemic based policies for supporting small businesses have not necessarily served the sector particularly well to date. Bennett's (2007) study of the expectations associated with the Business Links scheme illustrates that, as with the hunting of the Snark, success can be elusive. When it finally appears to be a prisoner, the Snark disappears, taking its captor with it. By looking for what was thought of as one thing - the Snark - the putative abductor, according to Carroll, has probably found something else; the Boojum, which is far more capricious a creature. This comparison illustrates the challenges faced by the numerous and diverse policy makers who are attempting to develop effective strategies, like the provision of advice, to support small businesses. The capturing of a successful strategy is challenging, like searching for the Snark. Care must be taken if something altogether different is not caught instead. In terms of advice, whilst for large firms it is widely expected that a comprehensive network of business support will be accessible, the situation is different in the smaller firm. In small firms, some of the decision support networks and mechanisms used by the larger firm are likely to be partly unfamiliar and unused (Hang and Wang 2012). In attempting to build and sustain competitive advantage, which is the key focus of this special edition, the circumstances are clearly different for the small firm. Despite there being copious material on SME information sources, scanty research appears to exist in relation to the tendency or otherwise, for SME decision-makers to actually utilise external advice (Burke and Jarratt, 2004; O’Donnell 2011). Pointedly, Berry et al., (2006), argue that further research is needed to understand how external advice is used.

The research reported here is drawn from representatives in the small manufacturing sector and the paper has four key aims. Firstly, it is intended to fill a general gap in the research literature referred to by Berry et al., (2006) regarding SME owner manager and business advisers. Secondly, the research is intended to establish whether SME owner managers perception is that the performance of their firm is enhanced, or not, by the use of a formalised external adviser and the system they work within. This is important, given the current context, where small firm advice is seen, despite economic and political change, as a central preoccupation of government (Gov.uk 2016). The third aim is to examine the perceived extent to which SME owner managers actually seek out advice, from external parties. Fourthly, the research will establish an understanding of both the factors encouraging the uptake of business advisers and the putative barriers that might discourage the use of external advice sources.The meeting of these research aims is likely to provide a very useful guide to government policy, business and marketing strategy for SMEs and also for future research in the area. The research calls on SME owner managers to recount their stories of business advisers within the broader narrative established here of Snark hunting and the potential capture of 'many benefits' (Carroll 2012; Hughes 2009).

Despite the view that there is a lack of expertise in terms of formalised information gathering and use, (Cacciolatti and Ferne 2012), the point is that small firm's importance to the economy must not be underestimated. It is widely accepted that there exists a positive relationship between entrepreneurship - often found in small firms - and economic growth (Deakins and 
Freel 2012). In particular, manufacturing small firms are viewed as both innovators and drivers of growth (Robinson and Pearce, 1984). In terms of definitions, according to Deakins and Freel (2012), in 2005, the European Commission redefined SMEs as those of less than 250 employees and an annual turnover and/or balance sheet that did not exceed $€ 50 \mathrm{~m}$ and $€ 43 \mathrm{~m}$ respectively. However, Deakins and Freel (2012) also suggest that whilst the European Commission recognises three sub-categories of micro enterprises, small enterprises and medium enterprises within the overall SME sector, it still tends to treat the small-firm sector as a homogeneous whole. Given the vast number of companies included in the sector and the huge diversity even within each sub-category, it would appear that any attempt to categorise small firms on a purely statistical basis might be problematic. This lack of attention to diversity and difference can have significant implications for business advice policy, with arguably, an undue focus being placed on ready-made generalised solutions that fail to adequately deal with the specific external and internal contexts in widely divergent types of firms (Mole 2007).

The discussion above of the papers research aims and the raising of some issues around business advice, has highlighted a need to clarify the emerging key themes. The further development of these themes, in the later parts of this paper, will assist the authors in focusing and contextualising the research and the stories the owner managers provide through the course of the interviews. The nascent themes are briefly outlined here. Firstly, there is the question of the extent to which owner managers are open to receive business advice from a consultant. A second theme concerns the degree to which the nature of this advice if taken, is of a standardised or tailored variety. The final theme deals with the level and role of trust in the relationship, that takes into account the advisers heritage and experience. The next two sections will consider some of the literature in the business advice area, followed by an outline of the methodology. Findings are then analysed and key implications discussed in the context of the aims of this paper and the three themes that have been identified.

\section{Stories and business advice: a theoretical perspective}

If we consider firstly the notion of business advice theories, then the work of Mole and Keogh (2009) point out that it can be divided into three types. There is firstly, the literature that sees business advice as supplement to the resources available to the manager. This resource based view (RBV) of the small firm, models growth on the basis of internal processes, where it is the characteristics, resources and capabilities that is the source of advantage (Lobacz and Glodek 2015). Importantly, advice therefore has to be tailored to the specific capabilities of each firm and the adviser needs to uncover the relevant information about the resources to hand. This might not be an easy task, as some of these resources might be difficult to identify. A further problem can be that if the consultant sees them self as primarily being a scientific expert, (Whittle 2006), enlisted to supply a codified replicable knowledge base, then it is possible that the result will not be a custom-made one that matches the individual firm's capabilities and resources.

The second strand of theory comes from the critical management literature. A critical perspective examines the basis and nature of any conflicts between the recipients of the advice, i.e. SME owner managers and the producer of that advice, namely the advising consultant. As Hu et al., (2014), indicate, a potential source of conflict - which could become a reality and then retold - might be where advisers simply commodify some management concepts and seek to persuade managers to adopt them. Their study also shows that the consultant will on occasions, adopt very directive roles, i.e., as technical experts and trainers, but that implementation is always subject to the various interpretation of managers and, if things go 
wrong, the consultant can be blamed (Adamson 2000). Conflict could then result. Also of interest here is the nature of any stories that recount reasons for owner managers rejecting or modifying in actual work practices, the advice of the external consultant, even if it appears initially that the advice might possibly result in benefits to the firm (Mole and Keogh 2009; Hu et al., 2014). Finally, there is the organisational development literature that forms a body of theory on business and consultancy advice. Here, the emphasis is on evolving actual activities between the adviser and the owner manager. Problems are there to be identified jointly. Subsequently, a journey of partnership is undertaken, which could result in a rich story, where developmental action means that both parties to the project will understand each other very well at the end of the process (Mole and Keogh 2009). The three perspectives outlined here provide a useful resource to help report and analyse the owner managers stories presented later in this paper.

\section{Snark hunting: external business advisers, the context and the literature}

Given the above background, there is some broad evidence available indicating that effective knowledge management i.e., knowledge of markets, customers, strategies and resources, can contribute to the long-term growth of the small firm, (see for example Blankson et al., 2006; Cacciolatti 2012). Ali et al., (2010) make the point that critical to a successful strategy is the learning orientation of firms, suggesting a role for external advisers, who can potentially contribute to this process. A further study suggests that those small firms with developed information systems that incorporate professional sources of advice will do better in the marketplace (Levy and Powell 2005). In support of this, Robinson and Pearce (1984) found that the impact of planning activity on small firm enhances performance when outsiders become involved in strategy development. In terms of our rendition here, it is important to see to what extent these points stand up to further scrutiny. In Carroll's story of the hunting of the Snark, an assorted array of characters set out in pursuit of the beast. In our adaption of the tale, those in pursuit of an effective policy for SMEs, includes not only government officials and consultants, but those who might directly do best by its capture, the owner managers themselves. Evidence suggests however, that rather than engage with external advisers, small firms usually use informal methods, trusted local sources and personal networking to gather decision-making information (Brush, 1992; Brouthers et al., 1998; Burke and Jarratt, 2004; O’Donnell 2011).

A relatively early study by Smeltzer et al., (1988) supports this. The authors identified that for nascent entrepreneurs, friends and relatives act as primary informal sources of both information and emotional support. Explanations for this state of affairs include the arguments that small business owners avoid seeking advice for fear of showing public ignorance (Curran and Blackburn, 2000) or, there is a dread of overdependence on the advisor (Zinger et al., 1996). This contrasts with the findings of Burke and Jarratt (2004). They attributed this preference to concerns over the credibility of advisors and the advice offered. They also found the reliance of small firm decision-makers on personal relationships and/or family members a result of the high level of trust in these networks. In line with key literature from relationship marketing that deals with networks (Morgan and Hunt 1994; Christopher et al., 2002), this issue of trust in partners for SMEs, is a view supported by Mole (2002). Use of personal relationships and existing close network partners is also evident in the work of Eisenhardt (1989) and (Gooderham et al., (2004). Both these studies found that small firms will turn to the existing professionals they use, such as solicitors and accountants for business advice, due to the longevity and nature of the relationship. 
In terms of decision making, Brouthers et al., (1998) established that small firm managers tend to rely heavily on their intuition to help deliver strategy, rather than formal inputs from a rationally determined external support system. For Mole and Keogh (2009), the smaller the firm the less likely they are to seek advice. The age of the company appears to have little impact on this state of affairs either. The study by McGee and Sawyerr (2003) identified that older SME firms still principally rely on internal information sources. With regard to younger organisations and given the purported need for more open variants of innovation, Mazzarol and Reboud (2006) established that small high innovator firms tend to place little value on external advice. Interestingly, in contrast, and in terms of context, the recent work of Lobacz et al., (2015), suggests small firms which are highly innovative, do in fact seek out and use external advisers. This tendency was evident when the strategic decision involved greater complexity. The further work of Jones et al., (2013), in developing a strategic network model for high technology SME firms, opens up the possibility for a sustained engagement with advisers, possibly through the companies' innovation, social, and importantly, its business networks. Also in terms of context, the work of Dyer and Ross (2008) found a link between the sensitivity of the environment and the use of external advisers. Those firms actively involved in dynamic and unpredictable environments were more likely to seek external information and advice. With particular reference to marketing information and advice, Gilmore et al., (2001), suggest that SMEs do not conform to the conventional characteristics of marketing textbook theories and marketing decision making is built on spontaneity, reactivity, informality and looseness. This suggests that a formal, planed reliance on external advisers is unlikely. The research of Jones and Suoranta (2013) and Jones and Rowley (2007), in their examination of entrepreneurial marketing and SMEs, raise the important point that in the pursuit of competitive advantage, interested parties need to understand how marketing evolves in SMEs as the business grows. One line of argument could be formulated from this insight, suggesting that growth might only come from the use of developed information systems involving outside contributors, like business advisers.

There is nevertheless, further influential marketing literature suggesting that central to the decision making process in companies other than very large ones, are the limited personal contact and social networks available to managers (Ellis and Meyer's 2001). The case currently, appears to be that any planned reliance on external advisers is not viewed positively by the small firm sector. As a justification of this general condition, Pineda et al., (1998), argue that a lack of awareness, accessibility and cost avoidance may all be reasons for a failure to seek out and use external advisers. O'Donnell (2011) has pointed out that in terms of information gathering about customers and competitors, advisers rarely feature. Instead, information is gathered through close links with staff and their clients. In addition, O’Donnell found that information on competitor activity is largely passive and informal. In summary, it is probably useful here to affirm the key point derived from a review of the literature that, "SMEs are surrounded by a plethora of institutions purporting to help them, most of which they ignore" (Mole 2007, p.586). There appears a marked reluctance therefore, on the part of many SMEs, to set out on a voyage to capture something they don't think will actually provide the benefits they require.

Also relevant here is the notion of entrepreneurial self-efficacy (ESE) (Bandura 1997; Chen et al., 1998; Forbes, 2005) and the extent to which the absence or presence of this disposition will either inhibit, or encourage, the business owner to engage with external advice. Any tendency towards over-confidence, with its attendant and possible deleterious impact on business decision-making, is evident in this concept. Forbes (2005, p.600) characterises ESE as an "individual's conscious belief in their own ability to bring about desired results". Alternatively, besides the existence of a strong belief and a high ESE, Stone (1994) interestingly suggests that decision-making and business performance is improved by mildly negative expectations. 
Hmielski and Baron (2009) found that experience in creating ventures helped to moderate entrepreneurial over optimism, where a reduction in the latter had a likely positive effect on firm performance. Here, Forbes (2005) supports the view of Bandura (1997) that an individual's ESE may change in response to important experiences. In terms of some of the wider findings on ESE, Hmielski and Baron (2008) also established that a high ESE could exert negative effects on business performance. The dangers of over confidence are probably selfevident, if we take into account the words of Cooke and Slack (1991, p.57) who describe how people, "tend to overestimate the true probability of events that are favourable to them". In this case, high levels of ESE might mean that external business advisers are not likely to be favoured. This apparently fixed situation might not be a constant though. While Chen et al., (1998) point out that ESE is a moderately stable belief structure, requiring continuous efforts to be changed, the case is that identities, personal stories and perceptions are often in flux, where they can be altered by events (Bauman (1995; Down 2010) Perhaps next year, a Snark will be sought, if a story has been formulated to show one is required, after all.

In terms of how small manufacturing businesses might receive advice, including the ones in this study and also for further information regarding the condition of the industry, we can turn to the Manufacturing Advisory Service (MAS). This was set up in order to provide support to manufacturing businesses in England, funded by what was then the department for Business Innovation and Skills (www.mymas.org/manufacturingsupport). In January 2013, MAS widened its scope of consultancy projects from a focus on specific manufacturing activity, to include supporting SMEs in the development of business strategy. MAS went on to reveal that the small and medium sized manufacturing business sector accounts for $\mathbf{1 1 0 , 0 0 0}$ businesses and 1.1 million jobs in England. At the same time, the MAS Barometer (2013) reported that 53\% of SME manufacturers reported an increase in sales, accompanied by $67 \%$ of respondents predicting further growth. These figures, despite the more recent issue of uncertainty for business around Brexit (Financial Times 2016), suggest reasons for optimism, in terms of opportunities for further growth and strategic development. In 2015, MAS activity was incorporated into the Business Growth Body (Business Growth 2015). However, this body was then closed down in early 2016, much to the disappointment of many small business owners (Business Forums 2016). However, based on recent policy indications from the government about a new industrial strategy and the importance placed on skills and training (Clark 2016), it is always possible that MAS will remerge in a different form. More generally, whilst it may be the case that government policy is in a state of fluidity with regard to providing business advice for the small manufacturing sector - something not that very unusual - the capture of a Snark, along with its benefits, can still be facilitated by the many private consulting organisations that exist (Enterprise Nation 2015).

\section{Methodology}

Much established research in entrepreneurial decision-making has commonly adopted quantitative techniques (O’Regan et al., 2005; Forbes, 2005; Mitchell et al., 2011). However, there is an emerging consensus within the literature towards using qualitative research methods for obtaining a deeper understanding of the influences on SME decision-making (Mador, 2000; Stokes 2000a; Ekanem, 2007; Hang and Wang 2012). In following on from this, the research adopts an interpretivist epistemological position since, in exploring the perceptions and attitudes of SME owner-managers, it recognises the role of humans as social actors (Silverman, (2013); Holstein and Gubrium (1995). One view is to see perception as an inherently social 
phenomenon, formed of contextualised social interactions and a self-narrative built around identity construction (Down 2010). In the study here, owner- managers build a narrative that draws on memory, life experience, interactions, stock of knowledge and cultural context (Gergen and Gergen 1983). In line with this, Mador (2000) utilises extensive empirical evidence (Dean and Sharfman, 1996; Eisenhardt and Zbaracki, 1992; Eisenhardt and Bourgeois, 1988) to show that the literature makes frequent calls for contextualised inquiry into the ways in which managers make choices. Mador (2000) in examining decision-making processes in an SME context advocates the gathering of decision stories in each of 5-8 SMEs. In addressing the key research issue of business support, the research here entailed semistructured interviews, where the question template used was intended to elicit narratives, in a storied form Hyde (2008). These interviews as narratives, were conducted by one of the authors, at a pre-agreed time in the interviewees own workplace, typically lasting $1-1 \frac{1}{2}$ hours. To give the study focus and to facilitate future systematic cross comparative analysis, the SME manufacturing sector was the basis for research. Bearing in mind the small number of companies featured the work here is intended not to test theory, but to generate theory in the area, (Marshall and Rossman 2015; Douglas 2003), with a view to stimulating further cross comparative analysis.

In pursuing this issue of research as stories, for Sims (1999) and Satre (2000), thinking is largely narrative in nature and central to the human condition. Similarly, for Watson (1994), telling and listening to stories is basic to the human process of making judgements about the world. For Hopkinson and Hogarth - Scott (2001), most of our understanding of the world is derived from the stories we hear or read and for Weick (1995), people use stories to understand action and meaning. None of this is less true of the small business owner, than of anyone else and as Fear (2014) illustrates, stories have been used as a way of understanding what happens in organisations and often as vehicles to achieve particular ends, such as implementing change. For the purposes of the research we adopt a perspective derived from the work of Gabriel (2000). He contends that stories have a distinctive form involving plots, characters and twists, composed of material that is full of meaning. In the examples here, stories are based on the experience of SME owner managers and their encounters with business advisers. The plots reported, involving the key characters of owners, staff and advisers, although they are short in length, entail all the criteria for a narrative. Present additionally, is conflict, emotion, predicaments, trials, successes, problems and crises all of which in turn, can call for choices, decisions and actions to be made and taken (Hyde 2008).

The criteria for selection was that firms should be privately owned and managed SME manufacturing businesses within a 20 mile radius of a designated East Midlands city. Firstly, owner/managers of thirty businesses were identified. Five indicated they were available for face-to-face interview. These interviewees were guaranteed total anonymity and a copy of the subsequent written findings. Participant entrepreneurs - as owner managers in the study - are involved in the following small scale manufacturing activities and are identified subsequently in the findings (although not by individual company at their request) as E1, E2, E3, E4, and E5. The firms are a bespoke sports garment manufacturer, an engineering and steel fabrication manufacturer, a wholesaler of animal supplies, a sub-contract manufacturer of engineering components and an engineering manufacturing company. The semi-structured interviews were largely conversational, in line with an attempt to elicit stories and also in keeping with the recommendations of Gilmore and Carson (2000) for conducting field-research with SME owner managers. In particular, this involved avoiding use of business research terminology, allowing interviewees to describe situations and perceptions in their own words. A pilot interview ensured that the questions worked satisfactorily. In the main part of the research, the 
interview approach that was used attempted to elicit dependable accounts of individual understanding (Silverman, 2013), so as to derive as much in-depth data as possible. The researcher adopted the criteria of a successful interview as described by Bryman \& Bell (2007), using an open, conversational approach, whilst attempting to listen attentively and with empathy. The verbal interaction was recorded, notes and an abbreviated transcription produced, from which the key themes of analysis were subsequently explicated.

\section{Company profiles and the interviewees}

A profile of the companies involved the research with some additional information about interviewees, was collected in the initial stages of the interview process. This was considered a useful way to build rapport with respondents. It was agreed not to individually tabulate company information, in order to help maintain anonymity. There are nine components to the general profile below and each component has been numbered consecutively.

1. Age of business - Although 2 of the 5 businesses had undergone restructuring in some way in the last three years, all 5 have been operating in the same or a similar form for at least the last 20 years. One company was over 180 years old.

2. Number of employees - The number varied from 9 to 100.

3. Turnover - this varied from $£ 0.75 \mathrm{~m}$ to $£ 19 \mathrm{~m}$.

4. Company size - 4 of the 5 participant companies fall within the European Commission definition of a Small Company. 1 fell within the European Commission definition of a Medium-sized Company. This organisation has very similar ownership, management structures and protocols to the other participant companies though.

5. Ownership - All companies were privately owned and majority owned, by either 1 or 2 individuals. E4 operates an employee share scheme.

6. Number of key strategic decision-makers - The number of key strategic decision-makers in each organisation varied from 1 to 6 and was found to be relative, but not directly proportionate to company size.

7. The interviewee's - 4 of the 5 interviewees were either Managing Director or Joint Managing Director of their organisation. One is neither the owner nor a director of the company, but as General Manager, has almost complete autonomy and is certainly the main decision-maker in the business.

8. Age - The ages of interviewees ranged from 44 to 73 years old.

9. Education and Experience - Only 2 of the 5 interviewees claimed to have higher education qualifications. Without exception, all interviewees placed little or no importance on this fact, stating that instead both business and practical experience in their particular sector was of much greater value to them than higher education.

\section{The SME owner manager: narratives and the role of advisers}

The paper now turns to the interviews. Generally, there was an acceptance amongst the owner managers of this study, that business advice might potentially represent an important resource. E3 commented that, "One thing that I'm wary of is becoming insular". In addition, the following comment from E2 suggest that whilst the bottom line of profitability is of 
paramount importance, there is a recognition that one of the aspects of successfully working a team is that their inputs are valued. This again suggests openness to ideas.

"Things are about numbers, it's about achieving the numbers at the end of the day. It's also about making sure that people are happy in their work."

Specifically, E5 addresses this issue of team input, expressing a preference for "the carrot rather than the stick." All businesses placed considerable value on feedback from customers as evidenced by this quote from E1, in responding to a question about information sources. "Market opportunities...definitely customers." Clearly, these organisations are close to their customers and appear to exhibit a notable degree of market responsiveness. This quote, along with the one above about an individual concern over narrow-mindedness, suggest that advice from customers and external advisers, are seen as critical resources to be used in line with the $\mathrm{RBV}$ perspective on the firm.

As already indicated in the literature review, this paper also raised the issue of Entrepreneurial Self Efficacy, in terms of the presence or not, of 'overconfidence' and its impact on the use of external business advisers. Here, the research interviews demonstrate that none of the entrepreneurs displayed evidence of excessive over-confidence. In fact, some were surprisingly candid in disclosing their view of their own fallibility. This was poignantly summarised in the response of E3 when it was stated, "You don't know what you don't know" The research found that all interviewees displayed levels of confidence, but not of over-confidence. All contributors were conscious of their own limitations and weaknesses and most displayed little resistance towards the need to rely on others, either internally or externally, to improve decision-making. In terms of this issue of over confidence, ESE was therefore not a major inhibitor towards entrepreneurial propensity for seeking help and advice in strategic decisionmaking. Although interviewees were not directly asked the question about the impact of their own personal life narrative on this issue, we can surmise that experience has taught them that over confidence can be a dangerous thing and risks are best taken in a calculated manner.

In considering explicitly the external business advisers role, there were some negative stories about their role, suggestive of conflict, regarding purposes and contribution. For example, E5 stated that,

"The one place we wouldn't go to is business advisers. I get the feeling that they don't really understand what the business is".

Here, the actual milieu of the firm is vitally important. The suggestion is that the adviser does not know already, or seek to find out, the local story of the business. It is the contingent nature of activity and the characters situations and plot lines that make each business a unique one. For E5, this issue is about the extent to which the external adviser can relate meaningfully to the business, because he said that, "Take a business like this, that's been around 23 odd years, I don't know what they can tell us". In a similar vein, E4 indicated that under the Growth Accelerator Scheme "the guy was rubbish really, he was telling our staff all sorts, so after 4 days we got rid". Here, it appears that the adviser is keen to get across their own story of how the firm should operate, one that apparently conflicts with what SME employees think it should be. One party here does not seem to be keen to grow the relationship, in contrast with the alternative organisational development model of the business adviser's work. 
The issue of knowing the business and its particular story, comes up again in the words this time of E4, who makes the point that,

"I wouldn't use them (consultants') for strategy. What do they know about our business? We operate in 40 countries around the world." E3 expresses similar sentiments. "Some of them come in and it's like Heinz 57....I think, how can you be a provider of such a broad spectrum of advice?"

A key theme here is that again, the local story is not being understood that well. It might be the case that an attempt to appear scientific and objective by the adviser, is alienating these small business owner managers. Perhaps equally negatively, but from a different perspective, E3 describes a less than positive experience, a result of several attempts to engage with a local university.

"The university has got a hell of a lot of resources and if I could tap into that effectively, that would be very good for my business but, it sort of fell into the university's bureaucracy; really, academics want to teach."

Alternatively in line with RBV thinking, here is a rich resource to be exploited, that if replicated more widely, suggests an opportunity exists for development. To illustrate this, and in contrast to the experience of E3, who was critical of universities, E4 discussed a more positive experience from collaborating with a local university in a consultancy context. Here, organisational development is occurring, as a joint effort between adviser and the client company. It was explained how the specialist knowledge derived from university academics, combined with a high level of student engagement, had proven to be highly beneficial. Great value was placed on the long-term relationship built with a particular academic. As a result, the company had engaged in several long-term Knowledge Transfer Partnership projects and had recruited key staff. The owner manager expressed strong intentions to continue this arrangement in the future, demonstrating the importance of context and relationships. A Snark has been caught in this case, not an ill serving Boojum, with some rich benefits accruing to the business as a result.

On a different resource base issue, an evident disincentive in taking on an external business advice relates to the issue of the cost of external consultants', as noted by E3 "As net borrowers we need payback in around 2 years otherwise it doesn't work for us." If a grant is available, then this helps to ameliorate the problem, and for E3, the case is that, "When there's a grant behind it, there's a hell of an incentive, because these people do charge a lot of money."

Despite there being some problematic issues with using advisers, there were additional stories here in support of external business advisers, indicating reasons why their services would be used by SMEs. As an example, E2 describes an affirmative experience, where they had engaged in a MAS funded consultancy project that addressed a specific production process issue.

"We're not specialists in everything. So, if we can get someone and they're specialists at it, then we let them get on with it." E2 then commented on the nature of the experience. "Good (and) you don't have to listen to everything, take the things that are relevant to your business".

So again here, it's not a reliance on a general prescriptive framework, but a careful picking through of the adviser's knowledge base, to see what works in the local situation. The following 
story from E3, supports this perspective, suggesting that rather than taking very general and perhaps abstract strategic advice, a clearly targeted consultancy approach is preferred, where measurement of a focused activity and a successful return, can be quickly arrived at.

"It varied according to who it was. We did BITs training and put 40 odd people through it....excellent! I've had others come in and frankly, they've replayed back to me what I knew. Then we had another one who came in and built our capacity model for us. He came in and timed everything and our production planner uses that matrix every day".

Here the organisation is being developed jointly, and additionally what emerges in this interview with E2, is the importance of trust and friendship, the latter a central feature of the plotlines in his story, and something built up over time. So, besides the specific MAS project,

"We have someone who comes in to us every month and he is someone that my business partner and I have worked for in the past. He has been MD of big companies." In pursuing this topic, E2 was questioned as to whether the consultant's role was similar to a nonexecutive director, or not. "Yes, without the title...and he is fantastic....he makes us take risk at times that we otherwise wouldn't; he does it, because we're friends".

In this case, there is then what is apparently, a high level of trust that the entrepreneur placed in the individual from whom he was receiving the advice. The advisor receives a nominal rate for his knowledge, but crucially, no ulterior motive or misplaced financial incentive is evident in his dealings with the firm. In widening the discussion here about relationships, the importance of trust also includes the role of credibility, where a common theme was the importance placed on the advisor having proven capabilities and a heritage. So it is very important that business advisers present their own credible and reputable stories about themselves and what they have done. E2 notes that in terms of legacy,

"I think it's important.... that they have a heritage....and they have a proven past." E1 went on to indicate "that the person I'm speaking with knows what they're talking about and that they can add value to the business."

Finally, E1 outlined a similar trust based story, involving a relationship with a consultant engaged in a project three years earlier. He explained that, subject to a small monthly fee, the consultant provided advice. They now continue to meet informally, to discuss strategic business matters and have become good friends in much the way described by E2 above.

SME owner managers and external advisers: research aims, themes and stories

Taking into account the findings reported, it would be appropriate initially to summarise the key themes that have emerged from the research. There are, as previously indicated in the introduction to the paper, three themes that the authors see as being present here. The first theme is about the role of information and knowledge in small manufacturing businesses. The research shows that owner managers are open-minded strategists' not insular egoists. They recognise their business have limitations and need new knowledge and information from time to time in order to remain competitive. Owner managers here, are willing to take advice from an outside source. They know this is a process that can add value and are not so over confident as to reject it, given the right circumstances. This point leads to the second theme. This can be summarised as tailored specialist advice 
works, not generalised prescription. The research suggests that whilst new business knowledge is important, there exists scepticism to the work of those advisers who see the implementation of universal prescriptions as being most suitable. They are often not, as indicated by some of the respondents here. In contrast, what is required, is specialised contextual knowledge and its application. Advisers need to understand the local stories of the firm and specifically know what is required. This may require a highly specialised input, as pointed out by respondents who would otherwise reject the work of the adviser. The third theme is that business relationship trust comes from engagement and heritage. Here, relationship strength cannot be built overnight and advisers have to prove their worth to the company over a period of time, where they work closely together. This process is helped if the adviser can tell a good story about their past business work. These key areas and their implications, will now be discussed at more length in the final two parts of this paper.

In reflecting firstly on the research approach adopted here, the general thrust was about seeking to provide evidence of entrepreneurial propensity to seek out and accept external advice as an input to a sustainable competitive strategy in an SME manufacturing context. The key methodological purpose of the interviews was an attempt to uncover SME owner manager's stories regarding their use of external business advisers, involving a degree of understanding, not only of the "how" but also of the "why". The research involved a small sample of participants and interviews were within a single industry sector and a concise geographical area, within a similar period. Therefore, whilst some relatively rich, meaningful data is present that has enabled some comparisons between respondents, the research does not make any claims for generalizability. Alternatively, the research here is best-evaluated using the criteria of soundness developed for interpretative research, rather than being overly concerned with replicability. The study's main aims and the data's relevance are made, clear, the research is situated in a scholarly and theoretically informed context, and the process of data collection and analysis have been explicitly documented (Marshall and Rossman 2015). In addition, as Kvale (1996) points out, the social constructionist perspective on interviews suggests that truth gets constituted through a dialogue and knowledge is not located in one overarching, external reality. Therefore, what comes across in the research here are the importance of individually framed stories. The relatively deep interview process led not to the elucidation of a one dimensional or unambiguous discourse on business support, but actually to the articulation of some nuanced viewpoints and perspectives. One of the benefits of analysing small-scale discourse is the ability to uncover the sometimes-multifaceted and contradictory nature of action that is manifested in language (Potter, and Wetherell 1987). In the next sections, the four aims of the research and the key themes will be examined, in terms of what has been discovered through the interview process. Interpreting owner manager's perceptions in the form of stories has resulted in the generation of material rich in plot and characters, enabling some detailed analysis to take place.

Firstly, an aim of the paper was to establish the extent to which the SME owner manager's perception is that the performance of their firm is enhanced, or not, by the use of a formalised external adviser and the system they work within. Generally, in line with some of the literature, (Ramsden and Bennett (2005); Berry et al., (2006); Łobacz, and Głodek, (2015), the research here shows that despite some degree of aversion to external advisers, there is evidence to indicate that owner entrepreneurs do support and recognise the value of business advice. Specialised targeted advice was seen to work well as with the example of specialised BITs 
training as indicated above by E3. Advisers were agreeable for use in explicit, time bound projects, but certainly not always in the case of developing long-term strategy. This type of ambiguous and conflicted knowledge is difficult to capture in tabulated form.

Importantly, whilst these small business people welcome support and advice in certain circumstances, they will hold it up to close scrutiny. This value recognition and use is therefore contingent, with a major inhibitor being trust and the credibility of the advisor. The comments provided by E1 and E2 reveal just how important trust is between the advisor and the recipient of the advice. Once trust is established, great value is put on the developing relationship, which leads to enhanced business performance. The further value placed on trust is indicated in E 4's references to the long-term relationship he had developed with university academics and ongoing KTP projects. Once trust had been established, great value was placed by the owner/manager on that source of advice, to the extent that they can became like close friends. Here, there are very interesting parallels with some recent research where ongoing work is beginning to establish that across cultures, loyalty arises between two people much easier than between companies and friendship has a pivotal role in defining and developing business relationships (Chen et al., 2015). To add to this, Nilsson (2015) points out how very important relationship oriented talk is, in the work of advisers in terms of building positive long term interactions and in overcoming difficulties. A second research aim here was to examine the perceived extent to which SME owner managers actually sought out advice, from external parties. Perhaps unsurprisingly, cost implications and lack of time and resources were reasons given for not engaging with consultants. Although not a key theme in the research here, the role of costs is worth close consideration by policy makers and consulting companies. So there is some evidence here to support the view of Pineda et al (1998) that SMEs are sensitive to the potential economic cost of external advice.

A third, research aim was an attempt to establish an understanding of both the factors encouraging the uptake of business advisers and the putative barriers that might discourage the use of external sources. One factor that did not inhibit uptake was the issue of the over confident owner - manager, as highlighted by the Entrepreneurial Self-efficacy concept and its impact on business adviser engagement. It was less significant than expected, judging from previous work (Forbes, 2005). Research here suggests it is not a key reason in explaining why small firms might avoid seeking external advice in decision-making. In addition, not a key theme, but equally not to be ignored like cost, is the influence of the external environment on the propensity of the SME owner to take on advice. At least one of the entrepreneurs indicated that the volatility and changes in external conditions affected their propensity to take risks, which could imply either employing, or not employing a business consultant.

In terms of barriers and in support of previous research of Brouthers et al., (1998) and Mole, (2007), there is evidence in this study of some small business entrepreneurial antipathy to the use of external advisers in decision-making. This is spite of some broad agreement in the literature that engaging with external business advisors can improve decision-making, and enhance business performance amongst entrepreneurs Forbes, (2005); Cacciolatti, and Fearne (2012). A very clear barrier to the further use of business advisers and a key theme that emerged, provided some evidence of the perceived stereotype of the consultant having only generalist knowledge that is not necessarily always applicable to particular situations. More broadly, the prescriptive, administrative based marketing and strategy literature does not always emphasise local and contextual factor sufficiently, with undue stress being placed on generalised rules of practice and theory (Miles et al 2015). This bears resonance with other entrepreneurial marketing literature that emphasises firm's particular situations. Instead, 
alternative concepts and tools are suggested that take local context more into account (Morrish and Deacon 2011; Hills et al 2008; Sethna et al 2013; Collinson and Shaw 2001; Stokes 2000b; Jones and Rowley 2009). Similarly, for other critically inspired marketing writers, the knowledge inherent in generalist marketing and business texts is little more than a broad selfserving rhetoric that offers prescription, but little in the way of local relevance (Hackley 2003; Brown 2006). And, not mentioned by respondents but nevertheless possibly being noteworthy in not terms of not using advisers, is the role played in decision making by tacit knowledge, where it is possible to speculate that local understanding is a significant factor, only possessed by those directly working and managing in the situation (Ardley and Quinn 2014; Mole 2007). Lastly, we argue this paper has made a contribution to the literature in the area by highlighting the key themes outlined above, the implications of which will be discussed in the final part of this paper.

\section{Conclusion: Relationships and the value of a Snark}

This paper has highlighted and discussed three key themes. These can be summarised as firstly, recognition that the owner entrepreneur is an open-minded strategist, not an insular egoist and secondly, is a business person who prefers tailored specialist advice over generalised prescription. The final theme indicates that the owner sees the establishment of trust in the client consultant relationship as a necessary central feature, an outcome that derives from a close engagement with an adviser with a strong heritage. In developing this discussion, the case is that advisers, in line with the theory we outlined earlier, can in different circumstances, be a rich resource, a cause of conflict and also, a means to develop the organisation. How these issues can be worked through will be considered as some implications are discussed about the future use of business advisers. Firstly, it can be argued some assessment of the owner manager's level of ESE might be useful to examine, as it could be utilised by, for example a consulting company to help tailor the nature of business advice. This might indicate a need to have ideas and decisions regularly checked and confirmed. Being involved in this type of process could be a useful one for a relevant external business adviser and their associates, along with the more familiar bases of information they can provide. Additionally a key issue might be about the need to understand more about the nature of ESE and the embedding of culture and experience in an owner manager's self-narrative. This could be an interesting area for future research, along with the impact of the external environment as a variable impacting on the SME owner manager's propensity to engage with an adviser. When times are bad, a Snark might be valued, as help is needed if it is not too costly. What does emerge particularly strongly from the research in terms of implications, is the suitability of the adviser to the specified firm and the nature of the relationship building efforts undertaken in the resulting engagement. A key to the plotlines of the stories provided here is trust.

Whilst the words and terms trust, relationship building and credibility are in wide use, the great challenge is to ensure that these interlinked issues are taken as contextually and locally relevant phenomenon. This focus on localised understanding, suggests that in individual cases, the relevant experience and knowledge of a prospective consultant is a factor that entrepreneurs should very closely examine. The nature of the story a consultant provides about themselves is crucial here, with credibility and heritage being the key words. Subsequently, how the external adviser goes on to interpret the local conditions faced by the SME in the light of existing patterns of knowledge is also significant. Trust consequently, is not to be conceptualised as an abstract concept, but is dependent on local circumstances and the perceptions of the owner managers involved. This process is of course, time and resource intensive, but once trust is established, it would seem likely that opportunities for long-term engagement and support will 
result, based on a mutual understanding of the local nature of doing business. Whether it is a short or long-term project, the careful selection of advisors and matching them to client needs will be a potential prerequisite in ensuring a degree of success. Work needs to be undertaken to improve any template used to select potential advisers, in order to ensure compatibility. As well as initially selecting appropriate advisers, any newer forms of government sponsored, or private consultancy service could also act first, as a trusted intermediary between the company and the individual adviser. Assistance could be provided to initiate the relationship between the client and the consultant, taking a role in screening out those advisers who might only be interested in short term financial returns, or lack the requisite skills. The subsequent advice provided is not to be seen as a quick fix solution however. The ownerladviser relationship will take time to develop as well as any nascent business strategy initiatives.

In terms of the Snark narrative that runs through this paper, in order to successfully 'capture' an appropriate policy, it has to be specific to the context of the organisation in terms of owner manager's views and the nature of the dialogue built with the adviser. Otherwise, the resulting initiatives might produce something else that is unwanted; i.e. a Boojum. A systemic inspired 'one policy for all' approach with generalist prescriptions, is unlikely to work and possibly will be subjected to a degree of scepticism from the small business owner, as indicated above in some of the interviews. The inherent weakness of the abstract and prescriptive type models of business and marketing is reinforced. This type of approach is probably currently being promulgated in terms of the myriad of consultant's who specialise in social media applications, who very keenly push a one dimensional view of its use, often without due regard to the contextual drivers of the businesses they are addressing. Given then the important caveat that advisers must understand the context of the SMEs they work with and seek to build trusting relationships, the case is that Snarks' are out there, waiting for capture, with clear benefits resulting. A challenge however, for all the characters involved in this particular story, is to make the capture cleanly, effectively and as cost efficient as possible.

As a final reflection, the dearth of existing literature in this area does suggest that more indepth interpretative studies of the nature of small firm engagement with external business advisors would be justified. Firstly, to be a comparison with findings here and because there is a good case for examining examples from outside the manufacturing sphere in order to consider similarities and differences. Secondly, more research can aid government-funded support organisations, private advisers and researchers, to develop successful, well targeted strategies for securing long-term involvement in improving and better understanding SME decision-making. This means that thirdly, owner managers may come to reflect more on the processes they adopt in developing sustainable competitive strategies and how business advisers can be best used to help deliver these, for mutual long term benefit. At the end of the day, perhaps this is the all-important story that needs developing and telling more widely. 


\section{References}

Adamson, I. (2000), "Management consultant meets a potential client for the first time: the preentry phase of consultancy in SMEs and the issues of qualitative research methodology", Qualitative Market Research: An International Journal, Vol 3No 1, pp17-26.

Ali, S. Peters, L. He, H. W, and Lettice, F. (2010), "Market based organisational learning, dynamic, and substantive capabilities: an integrative framework", Journal of Strategic Marketing Vol18 No. 5, pp363-377.

Ardley, B. C. and Quinn, L. (2014), "Practitioner accounts and knowledge production: an analysis of three marketing discourses”, Marketing Theory, Vol. 14 No. 1, pp. 97-114.

Bandura, A. (1997), Self-efficacy: The Exercise of Control, Freeman, London.

Bauman, Z. (1995), Life in Fragments: essays in postmodern morality, Basil Blackwell, Oxford.

Bennett, R. J. (2007), "Expectations-based evaluation of SME advice and consultancy: an example of business link services", Journal of Small Business and Enterprise Development, Vol 14 No3, pp435-457.

Berry, A. J. Sweeting, R. and Goto, J. (2006) "The effect of Business advisers on the performance of SMEs”, Journal of Small Business and Enterprise Development, Vol 13 No 1, pp33-47.

Blankson, C. Motwani, J.G . and Levenburg, N. M. (2006), "Understanding the patterns of market orientation among small businesses”, Marketing Intelligence and Planning, Vol. 24 No. 6, pp 572-590.

Brouthers, K.D., Andriessen, F. and Nicolaes, I. (1998), "Driving Blind: Strategic DecisionMaking in Small Companies”, Long Range Planning, Vol. 31 No.1, pp. 130-138.

Brush, C.G. (1992), "Marketplace Information Scanning Activities of New Manufacturing Ventures”, Journal of Small Business Management, Vol. 30 No. 4, pp. 41-53.

Brown, S. (2006), Retro Marketing, Sage, London.

Bryman, A., and Bell, E. (2007), Business Research Methods, Oxford University Press, Oxford.

Business Forums (2016) http://www.ukbusinessforums.co.uk/articles/how-the-businessgrowth-service-closure-affected-us.214/ (Accessed $12^{\text {th }}$ October 2016)

Business Growth Service (2015) Available at: www.mas.businessgrowthservice.greatbusiness.gov.uk/ (Accessed 15 ${ }^{\text {th }}$ June 2015)

Burke, G.I, and Jarratt, D.G. (2004), “The Influence of Information and Advice on Competitive Strategy: Definition in Small and Medium-sized Enterprises”, Qualitative Market Research: An International Journal, Vol. 7 No. 2, pp. 126-138. 
Cacciolatti, L.A., and Fearne, A. (2012), "Marketing intelligence in SMEs: implications for the industry and policy makers”, Marketing Intelligence and Planning, Vol. 31 No 1, pp 426.

Carroll, L. (2012), The Hunting of the Snark, Tundra Books, New York.

Chen, C.C, Greene, P.G, and Crick, A. (1998), Does Entrepreneurial Self-efficacy Distinguish Entrepreneurs from Managers? Journal of Business Venturing, Vol. 13 No. 4, pp. 295-316.

Chen, N, Ardley, B. and Zhao, Q. (2015), The impact of personal connection on customer behaviour (word of mouth intention and retention) in service encounters, in Proceedings of the $3^{\text {rd }}$ International conference on Contemporary Marketing Issues, 30 June $2^{\text {nd }}$ July Kingston University, London.

Christopher, M, Payne, A, and Ballantyne, D. (2002), Relationship Marketing: Creating stakeholder value, Elsevier Butterworth Heinemann, Oxford.

Clark, G. (2016), The importance of industrial strategy (speech) to the Institute of Directors annual conference $27^{\text {th }}$ September, available from https://www.gov.uk/government/speeches/the-importance-of-industrial-strategy (Accessed 12th October 2016)

Collinson, E, and Shaw, E. (2001), "Entrepreneurial marketing - a historical perspective on development and practice”, Management Decision, Vol. 39 No. 9, pp. 761-766.

Cooke, S, and Slack, N. (1991), Making Management Decisions, New York, Prentice Hall.

Curran, J. and Blackburn, R. (2000), "Panacea or White Elephant? A Critical Examination of the Proposed New Small Business Service and Response to the DTI Consultancy Paper”, Regional Studies, Vol. 34 No. 2, pp. 181-206.

Dean, J, and Sharfman, M. (1996), "Does Process Matter? A Study of Strategic Decisionmaking Effectiveness”, Academy of Management Journal, Vol. 39 No 2, pp. 368-396.

Deakins, D, and Freel, M. (2012), Entrepreneurship and Small Firms, London, McGrawHill.

Douglas, D (2003), Inductive theory generation: A grounded approach to business inquiry Electronic Journal of Business Research Methods, Vol 2 No 1, pp 47-54.

Down, S. (2010), Enterprise, Entrepreneurship and Small Business, London, Sage.

Dyer, L.M, and Ross, C.A. (2008), "Seeking Advice in a Dynamic and Complex Business Environment: Impact on the Success of Small Firms”, Journal of Developmental Entrepreneurship, Vol. 13 No. 2, pp. 133-149.

Enterprise Nation (2015) Top 50 business advisers 2015 announced available from https://www.enterprisenation.com/blog/posts/top-50-business-advisers-2015-announced (Accessed 12th October 2016) 
Eisenhardt, K.M. (1989), Making Fast Strategic Decisions in High-Velocity Environments, Academy of Management Journal, Vol. 32 No.3, pp. 543-576.

Eisenhardt, K., and Bourgeois, L.J. (1988), "Politics of Strategic Decision Making in HighVelocity Environments: Toward a Midrange Theory”, Academy of Management Journal, Vol. 31 No. 4, pp.737-770.

Eisenhardt, K, and Zbaracki, M. (1992), “Strategic Decision Making”, Strategic Management Journal, Vol. 13, No. 2, pp.17-37.

Ekanem, I. (2007), “Insider Accounts: A Qualitative Research Method for Small Firms”, Journal of Small Business and Enterprise Development, Vol. 14 No.1, pp. 105-117.

Ellis, N, and Meyer, R. (2001), "Inter organisational relationships and Strategy Development in an evolving Industrial network: Mapping Structure and Process”, Journal of Marketing Management, Vol. 17 No.1\2, pp183-223.

Fear, W.J. (2014), What is the story? "The Uniqueness Paradox and the Patient Story in the Minutes of the Boardroom”, Management Learning, 2014, Vol. 45 No 5, pp317-331.

Financial Times. (2016), Brexit Briefing: Economic cost of uncertainty, Available from https://www.ft.com/content/b3c595ac-80b8-11e6-bc52-0c7211ef3198 (Accessed 12th October 2016).

Forbes, D.P. (2005), “The Effects of Strategic Decision-making on Entrepreneurial Selfefficacy”, Entrepreneurship Theory and Practice, Vol. 29 No. 5, pp. 599-626.

Gabriel, Y. (2000), Storytelling in Organizations: Facts, Fictions and Fantasies, Oxford, Oxford University Press.

Gergen, K, and Gergen, M. (1983), “Narratives of the Self” in Sarbin, T.R. and Schiebe, K.E. (Eds) Studies in Social Identity, Praeger, New York.

Gilmore, A, and Carson, D. (2000), "The Demonstration of a Methodology for Assessing SME Decision Making”, Journal of Research In Marketing and Entrepreneurship, Vol. 2 No. 2, pp. 108-124.

Gilmore, A, Carson, D. and Grant, K. (2001), “SME Marketing in Practice”, Marketing Intelligence and Planning, Vol. 19 No. 1, pp. 6-11.

Gooderham, P.N, Tobiassen, A., Doving, E, and Nordhaug, O. (2004), “Accountants as Sources of Business Advice for Small Firms”, International Small Business Journal, Vol. 22 No. 1, pp. 5-22.

Gov. UK (2016) Business finance and support. Available at https://www.gov.uk/browse/business/finance-support (Accessed 9th October 2016)

Hackley, C. (2003), Marketing and Social Construction, Routledge, London. 
Hang, X, and Wang, C. (2012), “Strategic Decision-making in Small and Medium-sized Enterprises: Evidence from Australia”, International Journal of Business Studies, Vol. 20 No. 1, pp. 91-110.

Hmielski, K.M, and Baron, R. A. (2008), "When Does Entrepreneurial Self-efficacy Enhance Versus Reduce Firm Performance”, Strategic Entrepreneurship Journal, Vol. 2 No. 1, pp.57-72

Hills, G. E, Hultman, C.M, and Miles, M. P. (2008), “The evolution and development of Entrepreneurial Marketing” Journal of Small Business Management, Vol 46 No. 1, pp 99112.

Holstein, J. and Gubrium, J. (1995), The Active Interview, Sage, London.

Hopkinson, G. C. Hogarth Scott, S, (2001) "What happened was...” Broadening the Agenda for Storied Research”, Journal of Marketing Management, Vol 17 No 1\2, pp27-47.

Hu. Q, Found, P. Williams, S. and Mason, R. (2014), “The Role of Consultants in organisational learning” Journal of Management Policy and Practice Vol 15 No 4, pp29-39.

Hughes, A. (2009), "Hunting the Snark: Some reflections on the UK experience of support for the small business sector”, Innovation: Management, Policy \& Practice, Vol. 11 No. 1, pp. 114-127.

Hyde, P (2008),"Working with stories: diverse tales of organizational life", Qualitative Research in Organizations and Management: An International Journal, Vol. 3 No 2 pp. 147 158

Jones, R. and Rowley, J. (2007), Entrepreneurial Marketing - a considered approach for further analysis, in Proceedings of the Academy of Marketing Conference Kingston University $3^{\text {rd }}-6^{\text {th }}$ July.

Jones, R. and Rowley, J. (2009) "Presentation of a generic "EMICO” framework for research exploration of entrepreneurial marketing in SMEs" Journal of Research in Marketing and Entrepreneurship, Vol. 11 No. 1, pp5-21.

Jones, R. and Suoranta, M. (2013), Entrepreneurial Marketing orientation in SMEs in (Eds) Sethna, Z., Jones, R., Harrigan, P., Entrepreneurial Marketing, global perspectives Emerald Bingley.

Jones, R. Suoranta, M. and Rowley, J. (2013) "Strategic network marketing in technology SMEs”, Journal of Marketing Management, Vol 29, No 5-6, pp 671-697.

Kvale, S. (1996) InterViews, Thousand Oaks, Sage.

Levy, M. and Powell, P. (2005), “ Strategies for growth in SMEs”, Elsevier ButterworthHeineman, Oxford. 
Łobacz, K., and Głodek, P. (2015), "Development of Competitive Advantage of Small Innovative Firm-How to Model Business Advice Influence within the Process” Procedia Economics and Finance, 23, pp 487-494.

Lobacz, K. Stawasz, E. Glodek, and Niedzielski, P. (2015), "How small innovative firms utilise business advice? Process based classification of business advice” in proceedings, of 5th Annual International Conference on Innovation and Entrepreneurship, pp113-122.

Mador, M. (2000), "Strategic Decision-making Process Research: Are Entrepreneur and Owner Managed Firms Different? ” Journal of Research in Marketing and Entrepreneurship, Vol. 2 No 3, pp. 215-234.

Marshall, C. and Rossman, G. (2015), Designing Qualitative Research, Sage, London.

Mazzarol, T, and Reboud, S. (2006), “The Strategic Decision Making Of Entrepreneurs Within Small High Innovator Firms”, International Entrepreneurship and Management Journal, Vol. 2 No 2, pp. 261-280.

McGee, J.E, and Sawyerr, O.O. (2003), "Uncertainty and Information Search Activities: A Study of Owner-managers of Small High-technology Manufacturing Firms”, Journal of Small Business Management, Vol. 41 No. 4, pp. 385-401.

Miles, M, Gilmore, A, Harrigan, P, Lewis, G., and Sethna, Z. (2015), Exploring Entrepreneurial Marketing, Journal of Strategic Marketing, Vol. 23 No. 2, pp94-111.

Mitchell, J.R, Shepherd, D.A, and Sharfman, M.P. (2011), "Erratic Strategic Decisions: When and Why Managers are Inconsistent in Strategic Decision-making”, Strategic Management Journal, Vol. 32, No. 7 pp. 683-704.

Mole, K. (2002), “Business Advisers’ Impact on SMEs - An Agency Theory Approach”, International Small Business Journal, Vol. 20 No. 2, pp. 139-162.

Mole, K.F. (2007), “Tacit Knowledge, heuristics, consistency and error signals”, Journal of Small Business and Enterprise Development, Vol.14 No. 4, pp. 582-601.

Morgan, R.M. and Hunt, S.D. (1994), “The commitment trust theory of relationship marketing”, Journal of Marketing Vol. 58 No. 3, pp20-38.

Morrish, S. C. and Deacon , J. H. (2011), “A tale of two sprits: entrepreneurial marketing at 42Below Vodka and Penderyn Whisky" Journal of Small Business and Entrepreneurship Vol 24 No. 1, pp113-124.

Manufacturing Advisory Service (2013) Available at: www.mymas.org/manufacturingsupport (Accessed $5^{\text {th }}$ August 2013).

Manufacturing Advisory Service Barometer (2013) Available at: www.mymas.org/news/mas-barometer-reveals-english-manufacturing-smes-are-ready-toinvest (Accessed 12 ${ }^{\text {th }}$ August 2013). 
Mole, K.F. and Keogh, W. (2009), "The implications of public sector small business advisers becoming strategic sounding boards”, Enterprise and Regional Development Vol 21 No 1, pp 77-97.

Nilsson, T. (2015) Rhetorical business: a study of marketing work in the spirit of contradiction, Sweden, Lund University.

O’Donnell, A. (2011), "Small Firm Marketing: Synthesising and Supporting Received Wisdom”, Journal of Small Business and Enterprise Development, Vol. 18 No. 4, pp. 781805.

O’Regan, N, Sims, M, and Ghobadian, A. (2005), "High Performance: Ownership and Decision-making in SMEs”, Management Decision, Vol. 43 No. 3, pp. 382-396.

Pineda, R.C, Lerner, L, Miller, C. and Phillips, S.J. (1998), “An Investigation of Factors Affecting the Information-search Activities of Small Business Managers”, Journal of Small Business Management, Vol. 36 No. 1, pp. 60-71.

Potter, J, and Wetherell, M. (1987), Discourse and Social Psychology, Sage, London.

Ramsden, M, and Bennett, R,J. (2005), “The benefits of external support to SMEs: hard versus soft outcomes”, Journal of Small Business and Enterprise Development, Vol 12 No 2, pp 227- 2443.

Robinson Jr, R.B. and Pearce II, J.A. (1984), "Research Thrusts in Small Firm Strategic Planning”, Academy of Management Review, Vol. 9 No. 1, pp. 128-137.

Sartre, J. P. (2000) Nausea, London, Penguin.

Sethna, Z. Jones, R., and Harrigan, P. (Eds) (2013), Entrepreneurial Marketing, global perspectives, Emerald, Bingley.

Silverman, D. (2013), Doing Qualitative Research, Sage, London.

Sims, D. (1999), “Organizational Learning as the Development of Stories”. In: Easterby Smith, M., Burgoyne, J., Araujo, L. (eds.), Organisational Learning and the Learning Organisation, London: Sage, pp. 44-57.

Smeltzer, L.R, Fann, G.L., and Nikolaisen, V.N. (1988), "Environmental Scanning Practices in Small Business”, Journal of Small Business Management, Vol. 26 No. 3, pp. 55-62.

Stokes, D. (2000a), "Entrepreneurial Marketing: A Conceptualisation from Qualitative Research”, Qualitative Market Research, Vol. 3 No. 1, pp. 47-54.

Stokes, D. (2000b), Putting Entrepreneurship into Marketing: The Process of Entrepreneurial Marketing, Journal of Research in Marketing and Entrepreneurship, Vol. 2 No. 1: pp. 1-16.

Stone, D.N. (1994), Overconfidence in Initial Self-efficacy Judgements: Effects on Decision Processes and Performance, Organizational Behaviour and Human Decision Processes, Vol. 59 No 3, pp. 452-474. 
Watson, T. J. (1994) In Search of Management culture chaos and control in managerial work, London, Routledge.

Weick, K. E. (1995) Sensemaking in Organisations, London, Sage.

Whittle, A., (2006), “The Paradoxical Repertoires of Management Consultancy”, Journal of Organisational Change Management, Vol 19 No 4, pp.424-436.

Zinger, T.J, Blanco, H., Zanibbi, L. and Mount, J. (1996) An Empirical Study of the Small Business Support Network-The Entrepreneurs’ Perspective, Canadian Journal of Administrative Sciences, Vol. 13 No 4, pp. 347-357. 